\title{
PSYCHOANALYSIS AS THE PATIENT: HIGH IN FEELING, LOW IN ENERGY
}

This paper examines the increasingly important role that affect is assuming in psychoanalytic research and practice. This rise in the centrality of affect has been at the expense of an independent role for motivation and a dismissal of any energy concept. Difficulties with this affect-first approach are identified and an al ternative offered that accords motivation an independent role and accommodates a useful energy concept. Research on esophageal atresia, addiction, and infant suckling are cited in support of this position.

$\mathbf{I}$

$\mathrm{n}$ recent years two trends have developed in psychoanalytic thinking that have affinities with current developments in psychology: (1) the conceptual and clinical dominance assumed by affect; and (2) the apparent disappearance of anything comparable to an energy concept. These two developments taken together, I will argue, effectively deny motivation, let alone drives, any independent role in psychoanalytic theory. Nevertheless, the energy concept, far from being discarded, is in fact incorporated into affect in various guises, with unhappy consequences.

To construct an affect-first theory, the concept of drive is replaced by the concept of physiological need having no a psychological or experiential standing until linked to an affect elicited by an object. Thus, affect-imbrued object relations are established as the initial building blocks of psychological being.

Three problems are created by this approach: (1) given that most physiological needs are psychologically silent (e.g., electrolyte imbalance), affect-first theories fail to explain why certain physiological needs (and not others) do become linked to affects and thus assume psychological relevance; (2) by eliminating motivation as an

Professor of Psychology, Department of Psychology, University of Michigan Medical Center; faculty member, Michigan Psychoanalytic Institute.

Submitted for publication November 9, 1995. 
independent factor, these theories fail to account for psychological agency, which becomes at best a derivative of early object relations development; and (3) although these theories posit dramatic transformations in development as a function of vicissitudes in early object relations, they cannot account for the passage from one stage to another because they lack a true energy concept.

I will offer alternative formulations based on considering motivation as independent of affects from the beginning of life and as constituting the basis of psychological agency. The energy concept will be revisited and shown to play a crucial role in any theory of psychological transformation.

In a concluding section, I will adduce evidence from empirical studies supporting the position that motivation must be considered independent of affect and that significant neonatal psychological developments occur in the absence of a responding object, thus pointing to the earliest, non-object-dependent origin of psychological agency.

\section{TWO REPRESENTATIVE AFFECT-FIRST THEORIES:} KERNBERG AND LICHTENBERG

I will start by quoting a number of diverse theoreticians for whom affect is central:

I view affects as the primary motivators of behavior [Kernberg 1988, p. 319].

[The] sexual drive ... derives its motivational power not from any energy but from the affects it triggers [Lichtenberg 1989, p. 224].

anxiety and guilt [are] the affects responsible for initiating conflict [Brenner 1976, p. 11].

"drives" or other mental "contents" are not intrinsically dangerous but become so only when associated with one or another dysphoric feeling [Schwartz 1988, p. 361].

[An emotion is] an integrated unit of experience consisting of (1) a distinctive perception; (2) an implicit wish and implied action (motive); (3) a typical expression (facial and/or postural) that is species-specific and in man is culturally adapted [Dahl 1979, p. 211].

our affective core touches upon these aspects of experience which are most important to us as individuals because it organizes both meaning 
and motivation; it also allows us to get in touch with the uniqueness of our own (and others') experience . . . [Emde 1988, p. 32].

These quotations, which have in common a major emphasis on the centrality of affect - even to the point at which affects are considered the cause of motives - come from sources, across the range of psychoanalytic thinking, from the structural theory to object relations to self psychology. Included are authors who are primarily clinicians and others who are primarily researchers. Affect, then, is an underlying theme cutting across theoretical perspectives. Schwartz proposes that the drives themselves, or for that matter any mental content, are not "intrinsically dangerous" and become so only by virtue of the affect associated with them. The classical conception of the four danger situations-loss of object, loss of love, castration anxiety, and loss of self-regard - are not "intrinsically" dangerous, according to this view, but become so only by association with distressing affects.

Our feelings are obviously significant players in experience, but it is not immediately clear what determines that a given circumstance will constitute a species-wide danger. We think we know what these dangers are, but do they become dangers only because they make us feel anxious? Freud reasoned that the loss of the object, for example, creates anxiety because it leaves the infant in a state of helplessness with respect to its needs. It wanted mother because it needed mother. This is the so-called anaclitic position, about which more later. The abandoned infant is left in a state of wanting, or what I would prefer to call craving, that I will also say more about later.

Now, I know it would be fatuous to contend that the infant is aware in a fully propositional sense that "if mother is not around my needs will not be met and that makes me anxious." But is it aware only of anxiety, or does it also experience a wanting, a desiring, a craving that remains ungratified? To anticipate a later issue, does the infant at the start experience only affects, and not its needs in the form of wants or cravings?

It is apparent from the quotations I have marshaled that the central experience of human beings is to be equated with feelings. This is most explicitly apparent in Dahl's definition of emotion, which incorporates cognitive, motivational, and expressive aspects.

In the quotation from Lichtenberg we notice still another significant tendency in current thinking: the sexual drive itself, Lichtenberg tells us, derives its motivational power not from any energy, but from the 
affects it triggers. Of interest in this formulation is that the sexual drive is depicted as essentially lacking in any strength of its own; rather, it must borrow its strength from the affects it manages to "trigger."

Not only is the danger situation defined by the associated affect, as we saw in the Schwartz quote, but motivational strength is itself a function of affect, as we can see from Lichtenberg's statement. We do not know how much we want something until we know how strongly we feel about it - on the face of it, a reasonable and not unusual surmise. Yet there is an intriguing dual role assigned the sexual drive by Lichtenberg: the drive first triggers the affect and then is swelled in strength by its intensity. When later I go into Lichtenberg's ideas in greater detail, we will see that the sexual "trigger" is a "physiological need" that does not take on a psychological status as a motive until amplified by the affect it triggers.

Let me briefly summarize what I would like to draw from these quotes. In the view of quite a few psychoanalytically oriented thinkers, affects (1) are the primary motivators of behavior, (2) provide motivation its urgency and strength, and (3) define what is psychologically dangerous.

Paralleling this development in psychoanalytic thinking is a quite similar development in psychology at large. In fact, one theoretician in particular-Silvan Tomkins $(1962,1963)$ - serves as the bridge between these developments. Broadly speaking, what has been happening in psychology is that motivation is absorbed within the framework of belief or judgment, on the one hand, or of affect, on the other. In social cognitive psychology, the concepts of schema and self-schema figure importantly (see Shevrin 1989). For some social cognitive theorists, motives are defined as goals considered to be subsystems within schemata. Thus, to use one kind of example, the restaurant/eating schema incorporates the goal to eat. That goal is the motive for the act of going to the restaurant and eating. But if we bear in mind that a schema is a representation of some previous set of feelings, wishes, and actions now currently active, then it is clear that this conception is tantamount to imagining that a sign saying "Eat! Restaurant This Way" is a motive for going to the restaurant and eating. What I mean to say is that a schema is a signifier, an abstract signifier at that, while a goal is simply a further elaboration of that signifier that need not itself constitute a motive for any behavior, let alone eating. We may go to a restaurant, sit down, and not eat. It depends on whether we are hungry, 
or on what other psychological vicissitudes the need for food has encountered in the course of our development.

The concept of conation (i.e., motive, impulse, drive) appears to be incorporated within the enlarged boundaries of affect or feeling. Again, perhaps the most influential theorist in psychology championing the primacy of affects is Tomkins, according to whom affects serve to amplify needs. Without this amplification, the latter would be of little significance to us. It is clear that Tomkins wishes to assert that affects, as inborn proclivities, are the means through which our physiological needs are endowed with importance, so that we learn to pursue them in order to bring about pleasurable affects. Lichtenberg explicitly acknowledges his debt to Tomkins.

For several of the authors quoted there is an interesting and curious implicit distinction made between needs on the one hand and motives on the other. Needs are defined more or less as particular biological, physical imbalances that acquire psychological significance through the offices of affects, which are therefore regarded as progenitors of motivation in its strictly psychological meaning. I will later go into greater detail as to how this is meant to work. For now, however, let us ask what is gained by placing affects in so central a role. Affects would seem to be much more readily observable and communicable than either needs or motives. In research on infancy, affects are reported to be the phenomena most evident to observers. Affects seem both tangible and powerful. And yet, could this salience attributed to affects in truth reflect a theoretical bias? Is it not also the case that we just as readily attribute wants to the infant when we say, observing a distressed child, that it wants to be fed or changed? But it is nonetheless true that the same affect state may be prompted by different wants, so that affects are more invariant than wants and thus offer themselves as more reliable. Let us now examine the difficulties attending this emphasis on affects.

I believe there are several. To start with, an entire class of experiences-described with words like wanting, desiring, craving, and wishing - is accorded no independent standing but rather is regarded simply as a feature of affects. But on what basis, it may be asked, other than the purely subjective, could one support the view that these experiences are in fact separate and independent psychological phenomena? Here I think psychoanalysis can be of some help. When we speak of gratifying or frustrating an impulse, are we talking about affects? Do we speak of gratifying a feeling, or frustrating a feeling? It seems to me it 
does violence to both the concept of feeling and the concepts of gratification and frustration to so join them. We may speak of experiencing, expressing, or suppressing a feeling, but it is hard to imagine gratifying or frustrating a feeling. Even in describing abreaction we do not speak of gratifying the feeling abreacted; rather we speak of a feeling of relief following its abreaction. I would submit that only experiences classified as motivational in nature can be gratified or frustrated. It is also the case that when we talk about motivations we talk about acting on them but not about expressing them. But feelings are quintessentially expressed. These semantic considerations are intended simply as an introduction to the problem. There are weightier considerations to be explored.

The need to distinguish gratification from simple feeling bears on the often misunderstood pleasure principle. The sheer subjective, affective experience of pleasure or unpleasure must be distinguished from the buildup and release of motivational tension that is inherently pleasurable and unpleasurable. Unfortunately, the same words are used to refer to two quite different psychological events. We would avoid confusion if the terms frustration and gratification were applied to motivational states and pleasure and unpleasure applied to affect states. It would then be possible to speak of gratifying an aggressive desire while experiencing a feeling of unpleasure (i.e., guilt). It would be possible also to speak of frustrating an aggressive desire and feeling pleasure (i.e., pride).

Let me now turn to a closer examination of several of these affectcentered theories, specifically those of Kernberg and Lichtenberg.

I have quoted Kernberg as asserting that affects are the "primary motivators of behavior." In the sentence immediately following the one quoted, he writes, "affects are gradually organized into libidinal and aggressive drives, indissolubly linked to object relations from the onset of individuation" (Kernberg 1988, p. 319). Similarly, in a later paper Kernberg (1992) asserts that "libidinal and aggressive drives are a hierarchically superordinate motivational system constituted by affects which are their 'building blocks' ..." (p. 210). For Kernberg, clearly, the drives are secondary to affects and are in fact derived from them.

Unlike Lichtenberg, whom we will consider next, Kernberg (1978) finds a place for an energy concept in the form of "affect cathexes," paradoxically sounding very much like Freud's early idea of an "affect charge" surrounding an idea that may be detached and transformed into anxiety. Affective cathexes, he writes, 
that is, the quantitative element or economic factor involved in the intensity of primitive affect dispositions, ... are activated in the context of primitive units of internalized object relations; affects actually are the organizers of such primitive units. Gradually, affects differentiate, and their quantitative or economic aspects become intimately linked with the organization of motivational systems, or drives, into the "libido" series and the "aggression" series. Later, affects have a crucial function in signaling the predominant quality of libidinal, aggressive, or combined libidinal-aggressive motivational systems. Their quantitative elements or "cathexes" originally reflected the subjective, intrapsychic impact of gratification or frustration of physiological needs, but gradually they depend more and more on the subject's total interpretation of the immediate affective arousal in terms of its meaning for self and object, in terms of ego values and superego pressures, etc. [pp. 339-340].

Note that it is the physiological needs, not the affects, that are gratified or frustrated. I believe that here Kernberg is struggling with a knotty problem - how does one leap across the mind-body gap? His solution is worth attention. Let us parse his last sentence into its constituent parts: (a) the quantitative elements or "cathexes" (i.e., affect cathexes) derive from the "subjective impact" of (b) gratification and frustration of (c) physiological needs. These last are clearly somatic and biological. I am as unhappy about using terms like gratification and frustration with respect to physiological needs as I am about using them in connection with affects, and for this reason: there are many physiological needs that have no psychological relevance. For example, we would hesitate to say that an electrolyte imbalance is either gratified or frustrated; rather, we would say using psychologically neutral terms, that the need for electrolyte balance was met or unmet. These terminological distinctions allow us to differentiate needs that are psychologically relevant from those that are not. But how does the individual know which is which? Freud finessed the problem by simply asserting that psychologically relevant needs (instincts) have their own "representative" on the psychological plane - a solution by definition. Kernberg seems loath to go this route, however, as it would give psychologically relevant needs a psychological status independent of affects (and of objects as well). He finesses the problem away by treating physiological needs as if they can be directly gratified or frustrated psychologically. He can then go on to talk about this gratification and frustration as the source of the "subjective impact" from which in turn the strength of the "affect cathexes" is derived. 
Freud's finesse was meant essentially to get beyond the purely physiological level of needs or the biological grounding of instincts, while leaving intact the autonomy of need, now elevated to the psychological status of a drive or impulse. Further, Freud's solution provides for communication, tension, and potential conflict between the biological source of the instinct (the physiological need) and its "psychical representative." Laplanche and Pontalis (1967) make the interesting point that the implied metaphor in the term psychical representative is that of a delegate literally representing the physical need, as a legislator representing a district. And just as a legislator may sometimes vote against the needs of his district or ignore them, depending on his own inclinations or forces acting on him from his political party or legislative colleagues, so may the "psychical representative" of an instinct achieve a degree of autonomy because of its participation as a mental, rather than simply as a physiological, event. Thus, as I will later elaborate, the "psychical representative" is an active rather than passive part of the mind.

Kernberg, in effect, reduces drive and impulse in Freud's sense to the level of physiological needs and then elevates these needs to the psychological plane as affect. Since affects form affective memories "incorporating self components, object components, and the affect state itself" (Kernberg 1975, p. 339), one can see where he is going and why: only by denying impulses independent psychological standing, and considering them to be physiological needs solely, can he incorporate self- and object relations into his theory along with the affects now serving drive or impulse functions. Affects as dynamic entities are essential to Kernberg if he is to achieve this end. Affects cannot be treated simply as experiential, expressive events, nor can they be treated as "derivatives" of drives or impulses as defined by Freud, for then there would be too many degrees of freedom operating between impulses and object relations.

As with Kernberg, for Lichtenberg (1988) motivations are initially needs. "Each psychic motivational system," he writes, "is built around a fundamental need, and each is based on behaviors clearly observable beginning in the neonatal period: (1) the need to fulfill physiological requirements; (2) the need for attachment and affiliation; (3) the need for assertion and exploration; (4) the need to react aversively through antagonism and/or withdrawal; (5) the need for sensual and sexual pleasure" (p. 60). In this definition, Lichtenberg includes "physiologi- 
cal requirements" along with requirements more fully psychological in nature. But how are these to be distinguished? Lichtenberg's answer is in substance very much like Kernberg's:

For each motivational-functional system, affects are central. Affects serve as a principal means of communication between infant and caregiver (as crying and interest and smile for attachment, hunger satiety for physiological regulation and nonnutritive sucking pleasure for the sensual-sexual system). Equally important, the triggering of affect that occurs inherently with the activation of each of the perceptual-action patterns amplifies the motivation and gives greater significance to the functional activity" [p. 61].

For Lichtenberg there is a hierarchy of development from the initially given "motivational-functional" systems:

Each motivational-functional system has a biological and neurophysiological base assuring survival. This is the "need" end of the hierarchy. Next in the hierarchy are elemental learning schemata which develop into increasingly complex programs of intentions and planning. At a still higher level are wishes in the psychoanalytic sense of symbolic representations of desires, aims, ambitions, goals, and ideals. All three levels - need in the form of basic requirements, intentions and planning in the form of perceptual-affective action patterns, and symbolic representation of wishes - persist throughout life [p. 70].

Note how, for both Kernberg and Lichtenberg, wishes and impulses are later and secondary developments, dependent on affects and on what Lichtenberg refers to as "intersubjective experience," Kernberg as "object relations." First we have physiological needs and innate action patterns, and only then do we have affective experiences with caretakers, out of which wishes, drives, and impulses derive secondarily, as a function of the affective interactions with caretakers. From both Kernberg's and Lichtenberg's point of view, we learn to wish, to desire, to want, as a function of interactions with a caretaker or, from Kernberg's perspective, with the internalization of these intersubjective experiences in the form of object relations. It is important to note that according to Kernberg and Lichtenberg, we do not simply learn what to wish for or desire, but we learn to wish and to want. Prior to object relations or intersubjective experience there exist automatic physiological needs or motivational-functional systems with innate action patterns, but no desires or wishing in the strictly psychological sense. 
The biological clay of the infant is molded into desire itself in the matrix of the intersubjective or object-relational. Parenthetically, one could observe that desire, far from guaranteeing our autonomy from others and from society, is instead hostage to society and to the particular object relations we happen to be born into. This is a point made by Lionel Trilling (1971) with regard to Freud's instinct theory.

For both Kernberg and Lichtenberg, it seems, the centrality of object relations is what drives their theories to deny the independent status of motivation or conation in general. As I have mentioned, Lichtenberg draws heavily on the theories of Silvan Tomkins. For example, the concept of affective amplification of needs, which serves a conceptual function similar to that of "subjective impact" and "affect cathexes" in Kernberg's thinking, is borrowed directly from Tomkins. In one way or another, some quantitative or dynamic factor has apparently to be introduced, and that leads inevitably to an energy concept, a subject to which we shall now turn.

\section{REVISITING THE ENERGY CONCEPT}

The indictment of the energy concept has been grounded in three objections: (1) the concept is "data distant" and impersonal and thus doesn't help us clinically; (2) it derives from a hydraulic and mechanical metaphor borrowed by Freud from nineteenth-century physics and misapplied to psychology as a way of shoring up his claim that psychoanalysis is a natural science; (3) the reality to which it would refer does not exist, nor is the concept's usefulness supported by related sciences such as physiology. In short, the concept of psychic energy is neither useful nor appropriate, nor does it refer to anything real. I would like to try to defend the negative of these three indictments: the concept is both useful and appropriate, and it likely refers to something real.

Let me start with another look at Kernberg's and Lichtenberg's positions. Because Kernberg does in fact use an economic point of view, while Lichtenberg appears to abjure one, it should be interesting to compare them.

Kernberg's position involves five stages: (1) there are certain physiologically given needs; (2) these physiological needs can be gratified or frustrated; (3) these gratifications and frustrations occur in a context of affect experience and object relations; (4) the particular nature of these gratifications and frustrations produces a "subjective impact" on affect 
states and gives rise to the affect-cathexes accompanying particular object relations and governing the way in which those relations are internalized; (5) these newly formed affect-cathexes and internalized object relations in turn give rise to motives and impulses or, in psychoanalytic terms, to libidinal and aggressive drives.

This schematic model is offered by Kernberg as providing the conceptual tools with which to understand how narcissistic and borderline disorders develop. Notice that the five stages in the model attempt to account for how physiological needs become psychological motives. In a certain sense these five steps constitute a psychological transforming machine, not conceptually unlike the steps necessary to account for the way in which a waterfall ends up lighting an electric bulb - a process whereby a powerful natural force comparable to physiological need ends up serving a purely man-made purpose comparable to the creation of libidinal and aggressive impulses in the matrix of specific object relations. Thus are the raw powers of nature converted to civilized uses. The manner in which this happens is schematically defined as a series of significant transformations.

Lichtenberg's position can be schematized as follows: (1) in the beginning are motivational-functional systems and associated action patterns, biologically and neurophysiologically grounded, that Lichetenberg refers to as needs; (2) affects amplify these needs in the context of intersubjective experience so that these needs become significant psychological events; (3) out of this affect amplification arise wishes - "symbolic representations of drives, aims, ambitions, and ideals" (1988, p. 70). Again the biologically given is transformed into the humanly experienced: physiological needs become wishes, desires, ambitions, goals, and ideals as a result of affect amplification and intersubjective experience. Here we have a transforming machine not too dissimilar from Kernberg's, though not explicitly based on an economic principle. It is not, however, without a quasi-quantitative conceptthe idea of affect amplification borrowed from Tomkins. Clearly, Lichtenberg means by amplification something more than sheer increase. There is some qualitative change occurring from the condition of physiological need or action pattern to that of wish, desire, etc.

In my schematic exposition of Kernberg's and Lichtenberg's models I have slipped in two ideas I must further develop. I have described their models in terms (1) of how one step leads to another and (2) of major transformations occurring from the first to the last step. 
We have been admonished to eschew "how" questions and that to talk about transformations may be begging an important question: What in psychoanalytic terms is a transformation? In place of how questions, what some like Schafer $(1976,1988)$ feel are of greater interest and importance are the reasons people give, either explicitly or implicitly, for their actions in the broadest sense of that term: "The reason I went to the store was to buy a dress." "The reason I hate you is because you always criticize me." Or, in a more complicated vein, "The reason I disclaim hating you and act as if I don't is that I won't allow myself to feel hate toward anyone." Or, finally, "The reason I love you consciously is that I hate you unconsciously and want to disavow that hate." The strength of the action language approach proposed by Schafer is that it cuts through the difficult problems encountered by impersonally stated theories when dealing with agency. In both psychological schema theory and psychoanalytic structural theory, the place of the agent is lost. Not so in action language. The agent is always the person, the subject of the verb, whether we are dealing with conscious or unconscious actions.

When, if ever, does the person as agent appear in Kernberg's and Lichtenberg's models? Clearly, not at the first stage of physiological needs or action patterns. At some point beyond that, the person as agent or actor may emerge, already the fateful product of adventitiously encountered gratifications and frustrations of biological needs and the object relations into which the person is born. It seems odd and paradoxical to refer to personhood and agency as products, and yet in Kernberg's and Lichtenberg's schemata they would need to be. And, if they are products, how does this product emerge out of the interplay of the biological, the psychological, and the social? What reasons, in the sense used above, can account for this development? It is hard to see what these might be in Kernberg's and Lichtenberg's models, where personhood or agency is in a sense granted the child by its caretakers and how they respond to its affect expressions and physiological needs.

Strangely, it is in Freud's impersonal instinct theory, I believe, that personhood is vouchsafed as a given by placing the psychical representative of an instinct (i.e., of a physiological need) at the heart of development. (This is likely why Trilling identified instincts as the guarantee of individual freedom.) I am here proposing, though it is hardly a novel idea, that instincts as psychological givens, not simply as biological needs, are from the start of life at the core of personhood or agency, which is consequently not a product or vicissitude of devel- 
opment, though it will certainly be affected by it. (As I will later suggest, a new term is needed for this "psychical representative," one that captures the requisite sense of experiential immediacy. I believe that craving is such a term.)

But no theoretical model, certainly not one of psychological development or therapeutic change - that is, no model attempting to explain change - can avoid accounting for the transitions (i.e., how one step or phase leads to another). Nor can it avoid identifying, in the change from one step to another, what is changed and what is conserved. Bear in mind that if nothing is conserved, if nothing remains the same, we cannot speak of development but instead must speak of revolution or of some discontinuous and unrelated sequence of events. Were we to see at one time a caterpillar and at some future time a butterfly, we would have no way of knowing that a metamorphosis had taken place. Only by learning that an orderly process of change, in which one organ is modified to become another, does metamorphosis make sense. It is this conservation through change, I suggest, that requires the positing of an energy concept. To justify this claim, a bit of terminological history is in order.

The terms energy and force (and, secondarily, work and power) have in our time been taken over by physics. That was not originally the case. Like all sciences, physics borrowed its terms from the language of everyday life. The very word energy, according to the Oxford English Dictionary, was originally introduced into English by the poet Sidney in 1581, who borrowed it from Aristotle. Aristotle used the term to refer to the force or vigor of written or spoken expression. The OED records Sidney's first use: "That same forceableness or energia (as the Greeks called it) of the writer." Certainly I do not wish to overlook the fact that these terms are to this day used in ordinary language in something of the same sense. But nowadays we cannot avoid a sense of using the terms metaphorically or by analogy with their use in physics, whereas we have an historical right, if you like, to use them unmetaphorically and not by analogy. In fact, use by metaphor and analogy goes in the other direction, from ordinary talk to physics.

The word energy, in brief, derives from the Greek word for work, ergon, and refers to the capacity to do work, so that when Aristotle or Sidney used the term, they had in mind that the writer or speaker, by the application of "forcibleness" or "energy" accomplished something - that is, a work or, as we might say, a "piece of work." It is not accidental that we refer to a work of art or that a musical composition is called an opus, 
the Latin word for work - they are the outcome of the "forcible" application of "energy." Energy, force, and work were linked together in human experience long before modern physics. For these reasons, as I have proposed elsewhere (Shevrin 1981), these terms should not be abandoned simply because they have become in large measure the property of physics, which has embedded them in "mechanical" and "impersonal" theories. Rather, we should return to their root meaning and see how they can be of benefit to us. I believe that this root meaning can be expressed in this way: "Doing something actively to something beyond its capacity to resist." This "something" can be either physical or mental. When we apply ourselves actively to a task and bring about its conclusion, we have - in the root meaning of the word—worked. My main point is that energy, force, and work are not intrinsically impersonal and mechanical, but are naturally a part of our experience of ourselves and of our actions and accomplishments.

Let me now apply these ideas to our problem. When a person says, "The reason I love you consciously is that I hate you unconsciously and want to disclaim that hate," or when an infant's wants or desires are gratified and it responds with pleasure and molding itself to the caretaker, I would contend that in both instances the individual is engaged in an action and is at work in as fundamental a sense as when a locomotive pulls a train. Further, in this fundamental meaning of work, the human sense antedates the mechanical one. The actions are transformative, involving both change and conservation. In principle, a concept of transformative work is the only way we can begin to account for the nature of transitions between stages or steps in a process of development. Otherwise we are faced with stochastic, discontinuous jumps, a kind of creation de novo with each new step, and we are left simply to assert that one step must follow another, though we cannot account for the transitions.

But I have with some regret just said that the concept of transformative work is in principle the only way we can account for change and development.

On the general level, the problem is self-evident. Without such a concept, our models of change (of any psychological variety) are dead in the water. I might well be challenged, however, to stipulate how exactly that concept can usefully be applied to psychic reality. Before I make a stab at responding to the challenge, let me first offer my attempted solution to the problem of relating affect, action, and motive as they bear on the 
issue of personhood and agency. I then hope to be in a position to see how far I can go in explicating the possible gains in applying the concepts of force, energy, and work to psychic phenomena.

\section{MOTIVATIONS AS CRAVINGS AND DESIRES}

As we have seen, various psychoanalytic writers and developmental psychologists have shifted theoretical interest from motives, instincts, and impulses as prime movers to affects and affect organization that interact with intersubjective experience or object relationships to generate motives and agency. On the basis of an initial physiological substratum of need, the infant responds with inborn affects to gratification and frustration of these physiological needs in the matrix of its object relations, out of which it develops the capacity to want and desire at the level of psychic experience. Prior to that point, we can say, the infant is a biological organism; afterward it is a person. I have suggested that in order to make these models work, it has to be assumed that physiological needs can be gratified or frustrated, thus mixing two disparate levels of discourse, the biological and the psychological, and creating the problem of how to discriminate physiological needs that are psychologically relevant from those that are not. This line of reasoning, I believe, necessitates viewing the very capacity to want or desire as a social product, with the further consequence that agency or personhood are social products also, and so not the guarantors of individual autonomy. Without society and its caretaking agents, we would not desire or want in any intrinsically psychological sense; we would be like clocks on the mantelpiece sounding an alarm every time a physiological need reached a certain imbalance. I believe that too much is given away by such approaches.

When Freud took the step of abandoning his neurology for psychology and posited a "psychical representative" of a biologically grounded instinct, he left us at sea as to what that psychical representative was like. Over the course of his efforts to come to grips with the relationship between mind and body, he changed his terminology in order to capture more of what he felt that relationship to be. Nevertheless, it is clear that he was never satisfied with his efforts. Briefly, in The Interpretation of Dreams Freud (1900) speaks of the "excitations produced by internal needs [that] seek discharge in movement, which may be described as an 'internal change' or an 'expression 
of emotion"' (p. 565). Already the main ideas are present, though the terminology will change. In time "excitation" will be replaced by "psychical representative" (1915a, p. 122) or "instinctual representative" (1915b, p. 152). The latter term was intended to allow for three different manifestations of the instinct: ideational, motoric, and affective. Only the first of these, however, is truly representational in nature, and as such it is the only one that can be said to exist unconsciously. The latter two are treated as discharge phenomena caused by an instinctual quota of energy and exist solely as dispositions to respond rather than as active unconscious agents, a role reserved for the ideational representative of the instinct. (Here we see Freud attempting to cope with the phenomena of transformation by using an energy concept.) The matter is further complicated by the role assigned by Freud to primal repression, which renders the psychical or ideational representative of an instinct forever unconscious, so that it exists in the unconscious as a kind of permanent undertow contributing the necessary "pull from underneath" that causes repression proper (1912b, p. 148). Yet it is important to stress that for Freud only the ideational representative is an active force in the mind, not motor discharge and - of special import to our discussion-not affect.

How can this active agent in the mind, present from the beginning of instinctual life, be further characterized? Clearly for Freud this agent is motivational in nature-why else talk about its connection to instincts? But what kind of motive is it? In an earlier paper I wrote with Povl Toussieng (Shevrin and Toussieng 1965) dealing with psychotic children, we proposed that at the start of life infants experience cravings, the earliest form of what later will develop into desires, wants, or impulses. A craving is an intense, peremptory want, which, we further posited, is experienced; that is, it is psychological in nature and not simply a silent physiological imbalance. There is an additional property of a craving as we then defined it: although it is more intense and peremptory than any desire felt later, it lacks experiential quality in the sense that the infant cannot tell from the craving what exactly it is that is craved. From the side of the infant, it craves without measure and without knowing what it wants; from the side of the caretaker, the infant is experienced as demanding and difficult to figure out. As a psychological event, a craving is capable of being gratified or frustrated. Further, I would argue, it is at the core of personhood or agency; in another terminology, it may be regarded as the first harbinger of self. 
William James, in his chapter on the consciousness of self, relates the most basic sense of self to the "primitive and instinctual impulses of our nature" (1890, p. 319). I would qualify that statement only so that the "primitive and instinctual impulses" would be understood not as purely physiological needs or imbalances but as primitive experiences of craving. Although Descartes may have equated agency and existence with thought, and many contemporary psychoanalytic writers equate them with feeling, I am proposing that in earliest infancy the Cartesian formula should be restated as "I crave, therefore I am." Moreover, rather than our motives being forces external to ourselves, pushing us into action, our motives are ourselves acting with "forcibleness" and "energy." A craving, protesting baby is doing no less.

What is the theoretical point of talking about cravings instead of physiological needs? The main purpose is to make it possible to conceive of the infant as an "I," however primitive, whose experience of "I-ness," though given from the start, is nevertheless contingent (but not entirely dependent) on gratifications and frustrations obtained in the matrix of affect-laden intersubjective experience. These later factors, though they will certainly determine much about how cravings fare, the quality of their satisfactions and frustrations, and the special importance of caretakers, will neither determine nor create the core of agency and personhood, as they appear to do in the Kernberg and Lichtenberg models.

A second theoretical point to emphasize the fact that affect experiences, as only one set of factors determining the subsequent development of desires, are not responsible for their very existence. That is already guaranteed by the prior existence of cravings. But something of vital importance is nonetheless contributed by object relations and affect experience: the cravings, originally experienced as empty of quality, of a sense of what the craving is about, take on their psychological qualities as sensuousness, hunger, etc. in the matrix of object relations. It is there the infant learns what its desires are, not simply what it is to desire. By giving the function of "psychical representative" the psychological content of craving, we can at a single stroke, at least theoretically, assure the independent origin of personhood and agency, while preserving the later options of impulse development stipulated in Kernberg's and Lichtenberg's models. The simplest way to put it, which I save for last, is that psychological being is present from the start of life; we need not account for any transition from sheer biological existence to psychological experience once life begins. Of 
course, what we do lose in this view is the idea that object relations are the fundamental determinants of personhood and agency. I am prepared to accept that.

Let me now try to apply the concepts of force, energy, and work, which I hope I have shown can be employed without risk of being mechanical and impersonal. I will introduce one terminological change: instead of work, which still carries a narrow physical connotation, I will use the term effort, which encompasses mental as well as physical work. I will qualify it with the adjective psychological.

It is not difficult to see that the longer you apply yourself to a task of whatever sort, the more psychological effort you are exerting. Thus, in the case of the infant at the start of life, the longer the baby craves in the sense I have defined, the more effort the child is exerting. In that neither infant nor caretaker can readily discern what a craving is about, it may go on for long periods, during which the baby will be expending considerable effort. Once cravings are replaced by desires whose qualities are known by the child and readily discernible by the caretaker, they may be gratified more quickly and with a smaller expenditure of effort. A qualitative shift has resulted in a greater efficiency of psychological effort on the part of both infant and caretaker. But what has been conserved? The simple answer is agency, in the sense of active personhood that I have equated with the psychological activity of craving. Agency has been conserved and raised to a new level insofar as the infant now knows what it desires, how and by whom its desires can be met, and how long it must wait.

An interesting implication can be drawn from this little exercise. If cravings are not adequately gratified in a timely fashion, it is likely that desires will not emerge or will do so unstably; when that happens, the individual sense of agency or personhood will either be maintained at the previous level of cravings or will be so undermined that the experience of agency is itself compromised.

Empirical support for this conceptualization of agency as an early motivational state or craving is provided by Dowling's observations of infants suffering from esophageal atresia (1977). Because of a birth anomaly, food could not pass directly from the mouth into the stomach for these infants. To survive they had to be fed directly by tube into the stomach. Thus, nature has contrived cruelly here to separate the experience of hunger and satiation through oral intake from the fact of nutrition itself. These infants could be fed entirely on an arbitrary schedule, 
unrelated to their experience of hunger. It happened in several cases that a child was fed not when it cried in hunger, but when the caretaker deemed it convenient. When no effort was made to coordinate a sham oral feeding with direct stomach feeding (the milk or food placed in the child's mouth would emerge from the side of the throat), the experience of hunger was totally separated from physiological satiation and striking and dramatic developmental difficulties ensued. Dowling noted in these children a "lack of consistent intentionality in interaction with the environment" (p. 219). One child would become "restless and intermittently fussy, but never forcefully and recognizably hungry" (p. 221). This lack of demand and interest extended to all major phases of early development involving gross musculature, like crawling and walking. Language development was generally normal, but often words were not used to make wants known. Escalona, as quoted by Dowling, described Monica at thirty-four months, the earliest recorded case of esophageal atresia:

In view of the occasional delicacy of eye-hand coordination, it is as if the child were able to do better but just did not care enough or declined to make the effort which would result in greater success. ... The above observation implies that the primitive or retarded nature of Monica's behavior may in part be referable to a lack of "motivation" rather than a lack of "ability." (These terms are here used loosely —hence the quotation marks.) Many aspects of Monica's behavior (and history) suggest that there is a weakness or defect in connection with normally present impulses for action and sources of gratification [pp. 19-20].

In these infants, the experience of hunger as a craving was in fact undermined, and the child's capacity for agency, for intentional action, appeared grossly impaired. Note that its physiological need was met by the caretaker, in several cases in the context of warm and responsive mothering, but that if this mothering was not coordinated with its state of craving, a significant developmental anomaly in the capacity for agency resulted, no matter how loving the caretaker. For these infants, their psychological "forcibleness" and "energy" were gone.

In a formal conceptual sense the same considerations apply to transformations in level of organization occurring during treatment. It is not unusual for a patient to be in an intensely anxious state brought on by unconscious claims on the analyst that the latter can hear as clearly as one hears a baby crying in the night, though the precise nature of the claims may be as difficult to identify. Then at a certain point the 
patient produces a fantasy or dream that clarifies for both the nature and meaning of the claims. From a formal standpoint, the condition of conflicted unconscious claims is akin to a state of craving marked by an enormous expenditure of psychological effort caused by the intensity and duration of the infant's claim. The shift to a fantasy is comparable to the developmental transformation from craving to desire. The fantasy often makes far clearer what the nature of the claim is and what makes it so conflictual. The expenditure of psychological effort is markedly reduced, and agency is raised to a new level of mastery. It is also worth noting that in the older child and the adult this formal regression to a state of craving is produced by repression, which prevents either patient or analyst from knowing the specific quality of the claim. At the same time, this formal regression to a state of craving at the level of neurosis needs to be distinguished from severe developmental arrests at the craving level, a condition found in addicts.

\section{RECENT EMPIRICAL STUDIES}

Recent findings in two areas of research-(1) neurophysiology of addiction and (2) the psychophysiology of early oral gratificationhave direct bearing on my thesis.

Addiction is usually considered to be an extreme pathological form of pleasure seeking, a condition in which nothing else matters but to achieve through the drug a state of bliss, no matter how ephemeral. This view of addiction should gladden the hearts of affect-first theoreticians, because it clearly implies that it is the desired affect state that drives, or motivates, the addictive behavior. Motivation appears to be derived from the affect, not the other way around.

Recent research by Berridge and Robinson (1995) demonstrates quite otherwise. Their investigations show that there are neuronal systems underlying wanting or craving that are quite independent of neuronal systems underlying liking or enjoying. This suggests that it is not the pleasure involved in drug use that drives the behavior; rather, it is this separate craving system that drives the behavior in the absence of pleasure. "The neural systems . . . most sensitized by drugs . ..," write these authors, "normally mediate a specific motivational process we call 'wanting'.... This psychological process is not 'liking' or pleasure, nor is it directly experienced in conscious awareness" (p. 72). 
The brain systems most likely involved in this state of wanting or craving are the mesotelenchephalic dopamine systems, which show "robust sensitization after repeated exposure to drugs such as amphetamine, cocaine, or heroin" (p. 72). Berridge and Robinson point out that measures of liking and wanting have been confounded in most previous research. They have succeeded in separating these two systems by massively depleting forebrain dopamine through lesions that destroy only dopamine-containing neurons. The result was that appetite was eliminated, but that pleasant and unpleasant responses were retained. However, electrical stimulation of these same dopamine systems resulted in feeding with no increase or decrease in pleasant or unpleasant responses. The absence of wanting did not affect liking; nor did the presence of wanting affect liking. They functioned as two independent but coordinate systems, neither derived from the other.

I suggest that these findings do not fit with the KernbergLichtenberg-Tompkins theory that motivation derives from affect states, but rather support my ideas that cravings are there from the start and are independently powerful (Shevrin and Toussieng 1965).

Let me now turn to research on the psychophysiology of early oral gratification. Again it is important to bear in mind that the affect-first thesis is based on the premise that the affective response of infant to caretaker serves to mediate physiological need reduction, which then gives rise to various motivations. We have already seen that physiological need is subserved by a neuronal system having psychological relevance as wanting or craving. Now I will cite evidence demonstrating that the developmental benefits of oral gratification are quite independent of other caretaking modalities, such as holding or cuddling, and bear a significant relationship to Dowling's findings on esophageal atresia.

Zeifman, Delaney, and Blass (1994) have reported that when newborn infants are given sucrose their heart rate will diminish and they will stop crying, markedly reduce gross activity, and bring their hands to their mouths. From previous research with rat pups, these authors were able to trace this calming effect to the activation of endogenous opiodes. When opiodes were counteracted with naxolone, the calming effect disappeared. Interestingly, in human newborns this absence of calming effect was found in the babies of mothers who during pregnancy were on methadone, another substance that depletes endogenous opiodes. The point I want to make is that significant calming can be produced in the newborn entirely through an act of 
oral gratification; in fact, this can be done (but should not be) without a caretaker present.

But the story begins to change with two- and four-week-old infants. With two-week-old infants the amount of sucrose needs to be increased fivefold for most of the same effects to be achieved. But it is with the four-week-olds that a remarkable change occurs. In the four-week-olds sucrose will have the same effects as in two-week-olds, but only when eye contact is maintained with the infant. Neither eye contact alone nor sucrose alone will result in calming. The authors conclude that "four weeks of age may be a transition period from calming by nonsocial proximate stimulation such as sweet taste, to calming by specific, distal social interactions with parents or caretakers" (p. 1098). For a period of some four weeks, that is, the human infant can be calmed by satisfying its cravings without the necessary presence of caretaker-infant engagement. But by about four weeks the satisfaction of the infant's cravings can occur only in the context of such engagement. To be sure, simply holding the baby, no matter how warmly or closely while engaging its gaze, is not enough to produce calming; this activity must be accompanied by the gratification of a craving. For the purpose in question, an object relationship is not essential in the first month, but then becomes coordinately necessary.

These results support the view that we are born with powerful cravings that assert our agency well before any affect is aroused by an object relationship. Addiction research supports the view that these cravings are independent of affect and exert a powerful effect on behavior. The esophageal atresia observations support the view that if the satisfaction of cravings is dissociated from the simple meeting of physiological needs, even in the context of an object relationship, disorders of motivation will result. The Kernberg-Lichtenberg thesis is not supported by these findings.

\section{CONCLUSION}

I believe that I have been able to show, both from a theoretical standpoint and by adducing relevant research evidence, that any theory based on considering affect and object relations as primary, and motivation as secondary, is subject to serious theoretical difficulties and is contradicted by research evidence. Rather, it is motivation from the start of life that constitutes the origin of agency, independent of object relations. Affects 
are not the primary motivators of behavior, as asserted by Kernberg. Nor does motivation draw its power from the affect it triggers, as asserted by Lichtenberg. Motivation as craving is independently powerful; it is the mental agency that both represents and responds to the demands made on the mind by instinct or physiological need.

The theory proposed here leads to some new questions: (1) If Freud is correct in surmising that the earliest psychical representative (or craving) is subject to primal repression, then is the craving infant in a state of psychological unconsciousness? In other words, does it have psychological being but of an entirely unconscious kind? (2) If so, then at what point does consciousness as such arise? At one month of age, as suggested by the sucrose feeding research ? At the point at which, as suggested by Freud, an identity of perception yields to an identity of thought? (3) What clinical implications, if any, follow from these considerations? An attempt will be made to pursue these questions in subsequent papers.

\section{REFERENCES}

BeRRIDGE, K.C., \& Robinson, T. (1995). The mind of an addicted brain:

Neural sensitization of wanting versus liking. Current Directions in Psychological Science 4:71-76.

Brenner, C. (1976). Psychoanalytic Technique and Psychic Conflict. New York: International Universities Press.

DAHL, H. (1979). The appetitive hypothesis of emotions: A new psychoanalytic model of motivation. In Emotions in Personality and Psychopathology, ed. C.E. Izard. New York: Plenum, pp. 201-225.

DoWLING, S. (1977). Seven infants with esophageal atresia: A developmental study. Psychoanalytic Study of the Child 32:215-256.

EMDE, R.N., (1988). Development terminable and interminable: Innate and motivational factors. International Journal of Psycho-Analysis 69:23-42.

FREUD, S. (1900). The interpretation of dreams. Standard Edition 4/5.

(1915a). Instincts and their vicissitudes. Standard Edition 15:111-140. (I9|5b). Repression. Standard Edition 15:141-158.

JAMES, W. (1890). Principles of Psychology. New York: Holt.

Kernnerg, O. (1975). Borderline Conditions and Pathological Narcissism. New York: Aronson.

(1988). Psychic structure and structural change: An ego psychologyobject relations theory viewpoint. Journal of the American Psychoanalytic Association 36:315-338.

- (1992). The psychopathology of hatred. In Affect: Psychoanalytic Perspectives, ed. T. Shapiro \& R.N. Emde, pp. 209-238. 
LAPLANCHE, J., \& PONTALIS, J.-B. (1967). The Language of Psycho-Analysis, transl. D. Nicholson- Smith. New York: Norton, 1973.

LICHTENBERG, J.D. (1988). A theory of motivational-functional systems as psychic structures. Journal of the American Psychoanalytic Association 36:57-72.

(1989). Psychoanalysis and Motivation. Hillsdale, NJ: Analytic Press.

SChAfER, R. (1976). A New Language for Psychoanalysis. New Haven: Yale University Press.

- (1988). Discussion of panel presentations on psychic structure. Journal of the American Psychoanalytic Association 36:295-314.

SCHWARTZ, A. (1988). Reification revisited: Some neurologically filtered views of psychic structure and conflict. Journal of the American Psychoanalytic Association 36:359-385.

SHEVRIN, H. (198I). The experiential foundations of the energy concept: An argument for its theoretical and empirical necessity in psychoanalysis. Presentation to a panel on Metapsychology: Its Cultural and Scientific Roots, American Psychoanalytic Association Spring Meeting, San Juan, Puerto Rico.

(1989). A new synthesis or introductory text: Can it be both? Review of Introduction to Psychodynamics: A New Synthesis, by M.J. Horowitz. Contemporary Psychology 34:1099-1100.

\& TOUSSIENG, P. (1965). Vicissitudes of the need for tactile stimulation in instinctual development. Psychoanalytic Study of the Child 20:310-339.

TomkIns, S.S. (1962). Affect, Imagery, Consciousness. Vol. 1. New York: Springer.

(1963). Affect, Imagery, Consciousness. Vol. 2. New York: Springer.

TRILLING, L. (197I). Authenticity and the modern unconscious. Commentary 52 (Sept.):39-50.

Zeifman, D., Delaney, S., \& Blass, E.M. (1996). Sweet taste, looking, and calm in two- and four-week-old infants: The eyes have it. Developmental Psychology 32:1090-1099.

Riverview Building

900 Wall Street

Ann Arbor, MI 48109-0722

Fax: 313-764-403I

E-mail:Shevrin@umich.edu 